\title{
'Over-the-counter' genetic testing: what does it really mean for primary care?
}

\author{
Imran Rafi, Nadeem Qureshi, Anneke Lucassen, Michael Modell, Frances Elmslie, Joe Kai, Maggie Kirk, \\ Nigel Starey, Sheila Goff, Paul Brennan and Shirley Hodgson
}

\begin{abstract}
The publication of More Genes Direct by the Human Genetics Commission is a timely reminder of the potential impact that 'over-the-counter' genetic testing (that is, a direct genetic test without the need for a medical referral) may have on the NHS. This article considers the relevance of current genetic research on complex common diseases and how this might translate into risk estimates for developing conditions such as dementia, cancer, and cardiovascular disease. The implications for primary care include the need to understand the current limitations of genetic testing and its commercial application over the counter, and the importance of continuing to make risk assessments using family history. The authors recommend caution in the premature introduction of over-the-counter testing without a sound evidence base.

\section{Keywords}

general practice; genetics; genetic testing; over-the counter.
\end{abstract}

I Rafi, BSc, MSc, PhD, MRCGP, MRCPI, senior lecturer, Primary Care Education, Department of Community Health Sciences (General Practice); F Elmslie, MD, FRCP, consultant in clinical genetics; $S$ Goff, $M S c, R N$, registered genetic counsellor; S Hodgson, DM, FRCP, professor of cancer genetics, St George's, University of London. M Modell, FRCP, FRCGP, DCH, professor, Department of Primary Care and Population Sciences, University College London. N Qureshi, MSc, DM, MRCGP, clinical associate professor in primary care; J Kai, clinical associate professor in primary care, University of Nottingham, Nottingham. A Lucassen, BMedSci, FRCP, DPhil, professor of clinical genetics, Wessex Clinical Genetics Service, Princess Anne Hospital, Southampton. M Kirk, BSc(Hons), $P h D, R G N$, DipN, professor of genetics education, University of Glamorgan, Pontypridd, Wales. N Starey, BSc, MRCGP, GPwSI, GP principal, Prestwood House Surgery, Swadlincote, Derbyshire. P Brennan, BMedSci(Hons), FRCP, consultant in clinical genetics, Institute of Human Genetics, International Centre for Life, Newcastle upon Tyne.

Address for correspondence

Dr Imran Rafi, St George's, University of London, Department of Community Health Sciences (General Practice), Cranmer Terrace, London SW17 0RE. E-mail: irafi@sgul.ac.uk

Submitted: 19 March 2008; Editor's response: 4 June 2008; final acceptance: 16 September 2008.

(C)British Journal of General Practice.

This article was originally online first. Cite this article as: Br J Gen Pract 2009; 59: 283-287. Advance online publication. DOI: 10.3399/bjgp09X395021

\section{INTRODUCTION}

The Human Genome Project completed the initial sequence of the human genetic make-up in 2003. This has led to a mushrooming of research into the links between genetic variants and disease. Commercial organisations have moved quickly to use this information to market 'direct-to-consumer' or 'over-the-counter' (OTC) genetic susceptibility tests, that is, those that are available without the need for a medical referral. This article considers what this may mean for primary care practitioners, by outlining the extent and limitations of relevant evidence.

Although OTC testing could apply to any genetic test, the discussion here is limited to the use of DNA tests where a particular genetic variant confers an only slightly increased or decreased risk of a common disease and, as such, might suggest whether a small predisposition to the disease exists. Such predictive (and therefore usually presymptomatic) testing has been already been offered for conditions such as Alzheimer's disease, breast cancer, diabetes, and cardiovascular disease. There has also been much discussion about the potential benefits in areas such as pharmacogenetics.

In many diseases such as breast or prostate cancer, or Alzheimer's disease, there is a small but significant subgroup of individuals in whom the disease has a very strong (monogenic) predisposition. The authors consider these subgroups to be outside the scope of this article: they assume (and hope) that predictive genetic testing for such single-gene disorders will continue to be organised through the NHS, with appropriate genetic counselling.

\section{HOW USEFUL IS GENETIC SUSCEPTIBILITY TESTING?}

The potential to develop genetic susceptibility testing has been facilitated by the advent of 'chip' technology. It has become possible to use microarrays to process and sequence hundreds of thousands of single nucleotide polymorphisms (SNPs). SNPs account for the most common type of variation found in the human genome. These have been tested in case-control studies to determine 


\section{How this fits in}

Commercial companies are now offering genetic tests over-the-counter directly

to the public without the requirement for a medical referral. The Human

Genetics Commission has expressed its concern about the clinical utility of

tests which are based on relatively early research evidence and most fall

outside the UK Genetic Testing Network of accepted genetic tests. Primary care

practitioners will increasingly need to respond to people who may be worried or

uncertain about the outcome and implications of these tests. To do so

effectively, they need to appreciate the importance of taking an accurate family

history, have an awareness of appropriate referral pathways to genetic services

and understand the limitations of genetic testing.

whether certain SNPs are more common in cases than controls and, therefore, possibly implicated in disease susceptibility. Statistical analysis can then be used to determine whether the genetic variation present in the population under study contributes to disease susceptibility. However, the reliability of such analysis varies and is dependent on the robustness of the original data.

In addition, the majority of SNPs that are tested only alter the relative risk (RR) of developing a disease to a small extent (for example, $R R<1.2$ ). Singularly, they have little effect on the risk estimate and it is only if an individual is found to possess several high- or low-risk alleles (that is, different versions of the same gene) that the relative risk may reach a level at which clinical management might be altered. For example, possession of six high-risk breast cancer susceptibility alleles could indicate that a woman might start mammographic screening before reaching the age of 50 years, whereas a woman with six low-risk alleles could delay screening beyond that age. ${ }^{1}$

For a genetic susceptibility test to be of clinical value, there needs to be evidence of clinical utility and also provision of adequate follow-up services. Several aspects of a test need to be considered;

\section{Box 1. Key determinants of the value of a genetic susceptibility test.}

- How robust are the data linking a particular variant with a disease risk (for example, is it just one publication or have the data been reproduced in several studies; was the study on a sufficiently large sample of cases and controls)?

What level of risk increase is required before a test is deemed 'useful'?

- How does one variant interact with other genetic variants (for example, is the risk different depending on other single nucleotide polymorphisms)?

What interventions are available for those found to be at increased risk? What is the evidence base behind these interventions? If none, is this made clear?

-What pre- or post-test information services are available?

What laboratory quality-control mechanisms are in place? these are listed in Box 1. However, for many OTC genetic tests there is little evidence that there are satisfactory answers to the questions highlighted in Box 1; as such, primary care workers should advise patients who are considering such tests accordingly.

\section{SHOULD OTC GENETIC TESTING BE MORE READILY AVAILABLE?}

Concern that commercial testing may not fulfil the criteria given in Box 1, as well as other evidencebased criteria, ${ }^{2,3}$ led to the publication of the Human Genetics Commission 2007 report, More Genes Direct. ${ }^{4}$ The Human Genetics Commission works as an advisory board to the UK government on the potential ethical, legal, and social impact of developments in genetics. The key recommendations of the report were that:

- genetic tests should only be offered by suitably qualified health professionals;

- there is a need for implementation of a code of practice relating to genetic testing that takes a European perspective into account; and

- there is a call for the restriction of advertising for genetic testing.

The commission also recommended that there be no advertising aimed directly at the general public, and that web-based information be more transparent for consumers.

One argument that commercial companies put forward for offering genetic tests is that it empowers the patient. They argue that this personalised form of preventative medicine enables the individual to have a choice in making their own lifestyle decisions based on their genotype, allowing early, individually tailored, health advice.

In contrast to some commercial organisations that have patented certain gene sequences, for example, BRCA1, research groups such as the Wellcome Trust Case Control Consortium have published genetic sequences in the public domain. Other commercial organisations are now able to use this open information to offer members of the public tests for susceptibility to common diseases. The public and media perception may be that certain diseases have a greater genetic component than they do in reality. One might also argue that opening direct testing of any type to the public, genetic or non-genetic, is desirable as it allows for freedom of choice and open access to medical tests. A concern, however, is that private testing will involve tests that have been insufficiently validated and have uncertain predictive value. A lack of provision of adequate medical advice within the commercial sector is not in patients' best interests. This may 
cause people to turn to their traditional healthcare providers for advice on the meaning of the results of such tests. Primary care professionals are likely to be in the frontline for such approaches.

\section{THE ROLE OF THE PRIMARY CARE AND SPECIALIST HEALTH PROFESSIONAL}

Primary care health professionals will be exposed to commercial testing both when patients are contemplating genetic testing and when they return after being given the results of such tests.

A recent systematic review highlighted the importance of family history in estimating risks for conditions such as cerebrovascular disease, colorectal cancer, multiple sclerosis, and prostate cancer. ${ }^{5}$ Individuals may seek advice because they are worried about their family history or, following the completion of a family-history questionnaire at the time of a new-patient registration, the primary care team may identify those who they believe will benefit from further discussion about their family history. At this stage, both the patient and the physician may be contemplating a genetic test. However, based on current levels of evidence, genetic testing may not necessarily be the most appropriate next step in the management of these patients.

As recommended in family-history guidelines, ${ }^{6}$ patients with significant family histories (that is, moderate to high risk) should be referred to specialist services. Here the appropriateness of genetic testing can be evaluated using well-established protocols. ${ }^{7}$ Detailed discussions will be based around the family history, the implications of testing for highly penetrant gene mutations, the limitations of genetic testing, the potential repercussions for other family members, and social implications such as the effect on insurance premiums.

Such discussion may lead patients to change their minds or defer testing until a future date. ${ }^{8}$ In contrast to OTC testing, ongoing support and post-test counselling is routine in specialist genetic services. Furthermore, within the NHS setting, results are stored in confidential records with access only granted to those health professionals involved in the care of that individual and their family. These issues should be borne in mind when considering the issue of OTC testing with patients.

It is also likely that patients may go to their GP surgery with printed information about a commercially available genetic test that they have had, even though they may not necessarily have had any family history indications for taking such a test. Although certain websites will help with the interpretation of such tests (for example, http://genereviews.org), it is unrealistic to expect primary care health professionals to be able to assess the validity and utility of genetic tests, not least because the number of new tests is increasing exponentially. However, there are some basic steps that can be taken with a patient, the most important of which would be to take a detailed family history. While exploring the family history with the patient, it may be possible to identify individuals who would benefit from referral to clinical genetic services, irrespective of the results of the genetic test.

Discussion in a genetics centre is likely to focus on whether knowing each individual's gene status will have a direct effect on management. The positive predictive value of a DNA test can be improved by information about the family history, ${ }^{9}$ particularly as this can indicate the possibility of a highly penetrant susceptibility genetic mutation being present in an affected individual in the family. Such strongly disease-predisposing mutations are not tested for by OTC tests. However, several SNPs could achieve a relative disease risk, which could prompt screening interventions such as early mammography screening.

\section{Legal considerations}

Individuals have a right to pursue both genetic and non-genetic testing outside the NHS. Reasons for so doing may include:

\section{- the speed or ease of testing;}

- the fact that results would not be recorded in their GP records (and thereby not affect insurance issues, for example); and

- empowerment.

At a broader societal level, through the increased popularity of commercial genetic testing there is a danger of reinforcing the 'genetic determinism' argument, that is, the view that disease is solely determined by genetic make-up, ignoring the impact of environment. ${ }^{10}$ The latter includes income, lifestyle, living environment, and nutrition.

The responsibility of health professionals is to maintain a non-judgemental and objective approach and to try and ensure that patients are protected from unnecessary or harmful procedures. Discussion in the consultation, as described above, should facilitate this objective. Primary care professionals should be aware that a positive genetic result can lead to psychological distress, not only for the individuals, but also for other family members. Primary care and specialist genetic counselling can offer a supportive role.

\section{WHAT DOES THE FUTURE HOLD?}

Currently, limited numbers of genetic tests are available within the NHS. Predominantly, those 
available will detect highly penetrant gene mutations. These are accessed through regional genetics clinical and laboratory units by clinical geneticists and specialist counsellors, or through health professionals with relevant genetics knowledge. For example, a haematologist testing for Factor $\mathrm{V}$ Leiden mutation test, which will show predisposal to thrombosis.

A genetic test is included on the UK genetic tests directory (http://www.ukgtn.nhs.uk/gtn/Search) when it meets standards based on the original US ACCE framework. This framework assesses analytical validity (the reliability of the genetic test), clinical validity (biological relationship between the genetic test and the clinical condition), clinical utility (whether doing the genetic test will influence outcome) and an understanding of the ethical, legal, and social implications of the test to be offered. It is also made clear in the framework for the genetic test under consideration what the target population is and the desired referral pathway. ${ }^{2,3}$ Based on this evidence, a gene dossier is produced; when it is accepted by the UK Genetics testing Network (UKGTN), a recommendation is made to the Genetics Commissioning Advisory Group (GENCAG) about the potential clinical benefit and use of this test. The framework ensures that a rigorous validation process is adhered to, and a formal assessment of the clinical usefulness of the test is done.

In future, several of the genetic susceptibility tests that are currently only available commercially could have gene dossiers endorsed by UKGTN and GENCAG and recommended for use within the NHS. This clinical history in the gene dossiers provides valuable information about the penetrance of these gene variants and gene-environment interaction. ${ }^{11}$ Although GENCAG may agree that a test should be included on the directory, local commissioners may decide not to fund the test. If the only intervention offered by identifying genetic predisposition is adopting a healthy lifestyle, commissioners may consider developing a campaign, aimed at the general population, that promotes the benefits of having a healthy lifestyle. This may be a better use of finite resources.

Giving targeted lifestyle advice to those identified from their family history, genetic testing, and other risk factors (using revised risk prediction charts) ${ }^{12}$ as being at greatest risk, ${ }^{13}$ may be a cost-effective approach, provided that the genetic tests provide an accurate and significant disease-risk estimate alteration. There is some evidence that individuals at increased risk may be more receptive to lifestyle change. ${ }^{14}$ Furthermore, if strong evidence emerges about gene-environment interaction, the beneficial effects of targeted lifestyle intervention may be more obvious, for example coronary heart disease risk associated with an interaction between apolipoprotein E4 gene and smoking. ${ }^{15}$

As the level of sophistication in technology increases over time, the interaction between many gene variants and the environment may emerge for the numerous polygenic and multifactorial chronic diseases that health professionals are exposed to in daily clinical practice.

\section{CONCLUSION}

The Human Genetics Commission feels that the majority of people seeking testing should be advised to receive genetic counselling and genetic-risk communication based on expert professional and (particularly in the research setting) objective assessment. The authors of this article endorse this view although, in practice, it is not possible to offer genetic assessment to everyone seeking such OTC genetic tests. They also acknowledge that this is a rapidly developing field and that a total ban on OTC testing is not appropriate.

Although the risk-estimate alteration from a single SNP is likely to be too small for clinical utility, the use of several SNPs may enable determination of sufficient increased relative risks in some circumstances to indicate preventative healthcare management. Some of the authors' concerns would be alleviated if commercial companies attached a warning to OTC tests to indicate their limitations based on current evidence and the low predictive value of most individual SNP tests. Good written information might go a long way to ensuring patients do not have inappropriate expectations from OTC testing.

The Human Genetics Commission has signalled that the public should be made aware of the limitations of the genetic information they may receive and interventions that might be provided depending on the results of OTC tests. Groups such as this, rather than being paternalistic, are trying to highlight concerns that an individual or their family may be falsely reassured or, alternatively, distressed by unreliable test results. As an example, commercial companies might discount the significance of a family history after false reassurance from such a test. ${ }^{16}$ It is important for non-specialists to understand the importance and principles of familial and genetic risk assessment and to keep up to date with the everchanging landscape that is clinical genetics.

\section{Competing interests}

The authors constitute the Executive Council of the Primary Care Genetics Society and the views expressed represent a consensus of opinion of the council.

\section{Discuss this article}

Contribute and read comments about this article on the Discussion Forum: http://www.rcgp.org.uk/bjgp-discuss 


\section{REFERENCES}

1. Pharoah PD, Antoniou AC, Easton DF, Ponder BA. Polygenes, risk prediction, and targeted prevention of breast cancer. $N$ Engl J Med 2008; 358(26): 2796-2803.

2. Burke W, Zimmern RL, Kroese M. Defining purpose: a key step in genetic test evaluation. Genet Med 2007; 9(10): 675-681.

3. PHG Foundation. 2007/2008 Evaluation and regulation of genetic tests and molecular biomarkers. Cambridge: PHG Foundation. http://www.phgfoundation.org/pages/work7.htm\#oecd (accessed 13 Oct 2008).

4. Human Genetics Commission. More Genes Direct. http://www.hgc.gov.uk/client/document.asp?DocId=139\&CAtegor yId $=10$ (accessed 29 Oct 2008).

5. Butterworth A. Family history as a risk factor for common complex disease. Cambridge: PHG Foundation, 2007. http://www.phg foundation.org/pages/family_history.htm (accessed 1 Oct 2008)

6. National Institute for Health and Clinical Excellence. Familial breast cancer: the classification and care of women at risk of familial breast cancer in primary, secondary and tertiary care (partial update of CG14). London: NICE, 2006. http://www.nice.org.uk/guidance/ CG41 (accessed 1 Oct 2008).

7. Lerman C, Shields AE. Genetic testing for cancer susceptibility: the promise and the pitfalls. Nat Rev Cancer 2004; 4(3): 235-241.

8. Harper PS, Clarke AJ. Genetics, society and clinical practice. Oxford: Bios Scientific Publishers, 1997.
9. Rich EC, Burke W, Heaton CJ, et al. Reconsidering the family history in primary care. J Gen Intern Med 2004; 19(3): 273-280.

10. Green MJ, Botkin JR. 'Genetic exceptionalism' in medicine: clarifying the differences between genetic and nongenetic tests. Ann Intern Med 2003; 138(7): 571-575.

11. Hunter DJ. Gene-environment interactions in human disease. Nat Rev Genet 2005; 6(4): 287-298.

12. Drenos F, Whittaker JC, Humphries SE. The use of meta-analysis risk estimates for candidate genes in combination to predict coronary heart disease risk. Ann Hum Genet 2007; 71(Pt 5): 611-619.

13. Burke W, Atkins D, Gwinn M, et al. Genetic test evaluation: information needs of clinicians, policy makers, and the public. Am $J$ Epidemiol 2002; 156(4): 311-318.

14. Qureshi N, Kai J. Informing patients of familial diabetes mellitus risk: How do they respond? A cross-sectional survey. BMC Health Serv Res 2008; 8: 37.

15. Humphries SE, Talmud PJ, Hawe E, et al. Apolipoprotein E4 and coronary heart disease in middle-aged men who smoke: a prospective study. Lancet 2001; 358(9276): 115-119.

16. Elles, R. A response from the Chairman of the British Society for Human Genetics to the ITV1 programme 'The killer within' broadcast on Thursday November 8th 2007.

http://www.bshg.org.uk/GeneticHealthresponseOFCOM1107.pdf (accessed 29 Oct 2008) 